\title{
Cultura do arquivamento audiovisual: armazenamento, acesso e recuperação da informação em ambientes digitais
}

\author{
Audiovisual archiving culture: storage, access and recovery of information in digital \\ environments
}

\author{
José Jullian Gomes de Souza \\ Mestrando em Biblioteconomia \\ Universidade Federal do Cariri \\ jullianjose64@gmail.com \\ Paulo Eduardo Silva Lins Cajazeira \\ Doutor em Comunicação e Semiótica \\ Universidade Federal do Cariri \\ paulo.cajazeira@ufca.edu.br
}

\begin{abstract}
Resumo
O presente artigo propõe a ideia de uma cultura do arquivamento audiovisual, visualizada no âmbito acadêmico a partir da produção audiovisual do curso de Jornalismo da Universidade Federal do Cariri. O objetivo é investigar como o armazenamento de documentos audiovisuais como os documentários e as grandes reportagens - desenvolvidos para o trabalho de conclusão de curso - contribui para acesso, uso e recuperação da informação. Além, de criar um sistema de memória audiovisual. A metodologia parte de uma abordagem quanti-qualitativa, a partir de estudo exploratório, visando mapear os lugares de armazenamento digitais. Dessa forma, compreende-se que há a necessidade da implantação de uma cultura do arquivamento audiovisual, para propiciar o armazenamento e o acesso a esses documentos que pertencem à memória social da universidade e da sociedade, uma vez que não são visualizadas as práticas de armazenamento, sobretudo, em ambientes digitais.
\end{abstract}

\section{Palavras-chave}

Ambientes digitais. Cultura do arquivamento. Documento audiovisual. Recuperação da informação. Universidade Federal do Cariri.

\begin{abstract}
This article proposes the idea of a culture of audiovisual archiving, visualized in the academic sphere from the audiovisual production of the Journalism course at the Federal University of Cariri. The objective is to investigate how the storage of audiovisual documents such as documentaries and major reports - developed for the course completion work - contributes to access, use and retrieval of information. In addition, to create an audiovisual memory system. The methodology starts from a quantiqualitative approach, based on an exploratory study, aiming to map digital storage places. Thus, it is understood that there is a need to implement a culture of audiovisual archiving, to provide storage and access to these documents that belong to the social memory of the university and society, since storage practices are not seen especially in digital environments.
\end{abstract}

\section{Keywords}

Digital environments. Archiving culture. Audiovisual document. Information retrieval. Federal University of Cariri. 


\section{INTRODUÇÃO}

A investigação acerca dos documentos audiovisuais jornalísticos universitários e o seu processo de arquivamento se apresentam como umas das discussões centrais da pesquisa de mestrado em Biblioteconomia da Universidade Federal do Cariri (UFCA). Entrelaçando os campos de estudo da Biblioteconomia, Ciência da Informação e Comunicação, busca-se ampliar e visibilizar os estudos tendo como objeto de pesquisa o audiovisual, uma vez que o referencial teórico sobre esse objeto ainda é pouco discutido no âmbito informacional.

No presente artigo, intenta-se colocar em discussão a ideia de uma cultura do arquivamento audiovisual, vislumbrada como uma possibilidade de manutenção, processamento, armazenamento, disponibilização e, principalmente, recuperação da informação, tendo como foco os ambientes digitais de informação. A concepção de uma cultura do arquivamento audiovisual perpassa a necessidade de procedimentos dentro do ambiente acadêmico e da produção de documentos audiovisuais, que podem ser identificados com ênfase no escopo do curso de Jornalismo - como no caso da UFCA.

O recorte dos documentos audiovisuais perpassa os documentários e as grandes reportagens, produzidas pelos discentes do curso como uma das opções de trabalho de conclusão de curso da graduação em Jornalismo. É visualizado que o acesso a tais documentos não é possível, visto que a sua disponibilização não ocorre, devido à falta de seu arquivamento, o que direciona a pesquisa para a proposta de uma cultura do arquivamento audiovisual dentro da cultura universitária - a partir das instituições de ensino superior federais. E, com isso, criar um sistema de memória audiovisual para o público interno e/ou externo à instituição.

Dessa forma, surge o questionamento: Como a prática de arquivamento audiovisual potencializa o acesso, o uso e a recuperação da informação em ambientes digitais de informação? Tal questionamento parte da concepção segundo a qual a cultura do arquivamento audiovisual propicia não apenas a criação de um sistema de memória, mas a relação e o contato dos usuários com a produção audiovisual jornalística discente da universidade.

Assim, aponta-se como objetivo geral compreender como ocorrem as práticas de arquivamento e disponibilização dos documentos audiovisuais nas plataformas on-line do curso de Jornalismo da UFCA. E, de modo específico, mapear as plataformas on-line de disponibilização; e propor bases teóricas para a construção de uma cultura do arquivamento audiovisual no âmbito acadêmico.

A metodologia perpassa uma abordagem quanti-qualitativa, a partir de estudo exploratório, apresentando estatisticamente o número de produtos audiovisuais produzidos pelo curso de Jornalismo de 2013 ao primeiro semestre de 2019. A busca por esses produtos foi realizada tanto na Biblioteca do campus Juazeiro do Norte, Ceará, quanto na coordenação do curso de Jornalismo. Posteriormente, realizou-se um mapeamento das plataformas digitais que poderiam funcionar como lugares de armazenamento e memória.

Neste sentido, compreende-se que os documentos audiovisuais do curso de Jornalismo - o documentário e a grande reportagem - não estão disponíveis para acesso tanto em sua forma física quanto digital. Não foi identificado nenhuma rotina de arquivamento, assim como o estabelecimento de uma cultura do arquivamento audiovisual, o que direciona esses documentos, suas informações e importância para um esquecimento dentro de uma sala ou gavetas desses ambientes informacionais. 


\section{A PROBLEMÁTICA DO DOCUMENTO AUDIOVISUAL}

A problemática que cerca o documento audiovisual é oriunda da própria forma de compreensão da área e dos profissionais, porém, vem sendo transformada com o decorrer do tempo e com as mudanças ocasionadas com o próprio conceito de informação. Assim, tem-se o conceito apresentado por Le Coadic (1996, p. 5), em que "A informação é um conhecimento inscrito (gravado) sob a forma escrita (impressa ou numérica), oral ou audiovisual e em um suporte.". Sob esse espectro, é possível pensar que o documento audiovisual contém informação, mas que está apresentada em um novo formato e suporte.

Assim, a informação audiovisual, contido dentro desses documentos, é construída a partir de múltiplos sentidos (imagem + som + texto). Ela é oriunda da formação desse tipo informacional, possuindo características próprias e sofrendo processos de alteração e transformação com o decorrer do tempo (SANTOS et al., 2018), cujo objetivo é transferir a informação.

Essa transferência ocorre através de uma produção documental que, conforme explica Buckland (1997), passou a visualizar nas imagens gráficas, fotográficas e audiovisuais uma nova possibilidade de tipos de documento e informação. Desse modo, as produções de caráter audiovisual são concebidas como documentos a partir do momento em que visam à transferência de informação para um determinado sujeito.

É essa questão de documento e de como esse documento foi sendo percebido, sobretudo na Biblioteconomia, em que se encontra uma grande discussão: a questão do documento especial. Mas, antes de compreender essa questão, é preciso definir o que é um documento audiovisual. O documento audiovisual pode ser caracterizado como um documento formado por "[...] sons e/ou imagens em movimento dispostos em um suporte (fita cassete, fita Beta, CD, DVD etc.)." (BUARQUE, 2008, p. 1) e destinado ao público, através dos diversos espaços informacionais.

Além disso, esses documentos possuem características específicas como: a) registro, transferência, percepção e compreensão da necessidade de um dispositivo tecnológico para a visualização do seu conteúdo; b) conteúdo visual e/ou sonoro que tem duração linear e c) comunicação do conteúdo como propósito, mais do que a utilização da tecnologia para outros propósitos (EDMONDSON, 1998).

Ao refletir sobre o documento e suas formas, Bellotto (1991, p. 14) explica que "A forma/função pela qual o documento é criado é que determina seu uso e seu destino de armazenamento futuro. É a razão de sua origem [...], e não o suporte sobre o qual está constituído, que vai determinar sua condição de documento de arquivo [...]". Dessa forma, o documento audiovisual nada mais é do que uma nova forma de representar a informação a partir de outro suporte, cujo objetivo permanece sendo o mesmo de um documento textual: a recuperação da informação.

Explicitado a definição de documento audiovisual, faz-se necessário compreender a denominação "documento especial", que determinados autores e o próprio processo histórico trazem como uma nomenclatura desses documentos. Para Pearce-Moses (2005), o documento especial é aquele que está armazenado separado de outros documentos, pois as suas características exigem tratamentos específicos ou seu formato é de grandes dimensões. Ele observa que, através de seu formato físico, os profissionais devem lidar com esses documentos, ainda que seja necessária a criação de novas técnicas ou modelos de tratamento.

Nessa mesma vertente, González-García (1992) propõe a criação de duas categorias para os documentos em novos suportes: documentos audiovisuais e documentos em suportes 
informáticos. Nesse segundo tipo de documentos, o autor se refere a presença de documentos iconográficos e/ou sonoros, que podem ser encontrados em novos suportes. Ou seja,

A utilização em larga escala de novas linguagens de comunicação fizeram os arquivistas [e bibliotecários] se interessarem por esses novos tipos de documentos, registrados em diferentes suportes: documento audiovisual (fitas videomagnéticas, filme e semeIhantes), documento iconográfico (filmes fotográficos, papel emulsionado e semelhantes) e documento sonoro (fitas audiomagnéticas, discos etc.). (VIEIRA, 2016, p. 48-49).

Neste sentido, a situação vai se modificando com a expansão de novos formatos, linguagens e possibilidades de arquivamento de documentos, sobretudo, com a linguagem audiovisual, iconográfica e sonora sendo incorporadas como novos tipos documentais. Com isso, já é possível identificar que a informação audiovisual e o documento audiovisual passam a ser vistos sob novos olhares seja na Biblioteconomia, Arquivologia, Museologia e Ciência da Informação. Essa mudança de perspectiva é fundamental, pois a sociedade contemporânea está cercada pelos mais diversos tipos de documentos e, dentre eles, destacam-se os audiovisuais - produzidos a cada instante e em alta velocidade.

Com isso, a organização do documento depende de práticas em que várias profissões e profissionais estejam envolvidos, pois o surgimento de um novo meio de comunicação, como o digital, e suas possibilidades permitiram o vislumbre de novas funcionalidades no que se refere ao conteúdo e ao produto audiovisual (SOUZA; CAJAZEIRA, 2015), principalmente na Biblioteconomia e Ciência da Informação.

\footnotetext{
Isso porque os documentos audiovisuais podem iniciar sua trajetória como um suporte de outra atividade na biblioteca, no centro de documentação, no museu ou no arquivo. De modo geral, podemos ter exemplos de uma documentação audiovisual através da atividade museológica, que busca preservar filmes como as bibliotecas preservam livros, ou como os museus e pinacotecas preservam quadros. (CAJAZEIRA; SOUZA, 2019, p. 125).
}

Neste horizonte, a documentação audiovisual permeia os contextos sociais, seja na comunicação, na educação, na biblioteca ou em outros setores informacionais. É necessária uma reflexão dos parâmetros de tratamento e gestão do documento audiovisual nesses locais, uma vez que a informação audiovisual tem grande importância no meio cultural.

Essa reflexão sobre a introdução de novas formas de documentos na Biblioteconomia e Ciência da Informação e em áreas afins é importante, pois possibilita compreender as transformações do campo, da sociedade e de como os profissionais, principalmente os bibliotecários, se apropriam dos documentos audiovisuais. O documento audiovisual não deve ser visto como algo exótico, mas como outra possibilidade de armazenamento, arquivamento e recuperação das informações, que se apresentam em meio a uma sociedade informacional em constante transformação. E, que essa tem sido pautada, principalmente, pelo uso de documentos para registrar e armazenar todo esse volume de conteúdo audiovisual produzido pelos discentes do curso de Jornalismo como, por exemplo, o documentário e a grande reportagem.

\section{O PRODUTO AUDIOVISUAL JORNALÍSTICO UNIVERSITÁRIO}

No âmbito dos documentos audiovisuais universitários, o enfoque dá-se sobre o produto audiovisual jornalístico decorrente da produção discente para a conclusão da graduação em Jornalismo. Nessa perspectiva, a análise tem como base a elaboração do Trabalho de Conclusão 
de Curso (TCC) da UFCA, partindo do documentário e da grande reportagem. Essas duas categorias de documento audiovisual perpassam a pesquisa e se configuram como recortes para o objeto de pesquisa: o documento audiovisual jornalístico universitário.

O chamado TCC é uma disciplina obrigatória na matriz curricular na maioria dos cursos de graduação. Nessa disciplina, o discente desenvolve uma reflexão teórica ou teórico-prática, dependendo do curso e da instituição, a partir do seu conhecimento adquirido ao longo dos semestres de disciplinas, discussões e aprendizados em sala de aula junto aos professores e aos colegas da turma. No Projeto Pedagógico do Curso de Jornalismo da UFCA (2016), a disciplina de TCC é ofertada no oitavo semestre, com carga horáriA de 320 horas. Tal disciplina é precedida por outra, Pesquisa em Comunicação, que é ministrada no sétimo semestre, em que o discente direciona a sua pesquisa e o seu modelo de TCC com o apoio do professor da disciplina.

As modalidades do TCC podem variar de instituição para instituição e de curso para curso. Especificamente no curso de Jornalismo da UFCA, encontram-se duas opções: a monografia e o produto jornalístico. A escolha de uma dessas duas possibilidades deve ocorrer no semestre anterior. Assim, o discente tem um ano para o desenvolvimento até o momento da defesa do seu TCC, como componente para o término da graduação em Jornalismo.

De acordo com o Projeto Pedagógico do Curso de Jornalismo,

[...] Produto Jornalístico permite que o(a) aluno(a) desenvolva, de forma experimental, a criação de um produto jornalístico que possa contribuir para o amadurecimento profissional. A disciplina está relacionada ao campo da experimentação, mas exige rigor necessário à realização dos trabalhos, partindo do pressuposto de que o(a) aluno(a) esteja apto(a) a ingressar formalmente no mercado de trabalho. É premissa fundamental para o desenvolvimento do projeto, que o trabalho a ser desenvolvido tenha ou viabilidade comercial (mercadológica) ou relevância cultural. (UFCA, 2016, p. 129).

É interessante observar com a possibilidade advinda do produto jornalístico, que o foco está voltado para o lado prático e experimental cujo objetivo é proporcionar ao discente um contato ainda mais próximo com o cotidiano da profissão. Em relação às modalidades de produtos jornalísticos, elas estão classificadas em nove categorias: 1) livro-reportagem; 2) revista; 3) jornal impresso; 4) plano de comunicação de uma assessoria de comunicação; 5) documentário fotográfico; 6) documentário televisivo; 7) grande reportagem televisiva; 8) documentário radiofônico; e 9) produção de um programa em formato radiorrevista ou produto multimídia (webdocumentário).

Dessas nove modalidades, destacam-se duas que estão intrinsecamente relacionadas aos documentos audiovisuais, a saber, o documentário televisivo e a grande reportagem. Assim, o contato com a produção audiovisual ocorre nas disciplinas Telejornalismo I (4ํ semestre), Telejornalismo II (5으 semestre) e Laboratório de Telejornalismo ${ }^{1}$ (60 semestre), nas quais os discentes podem se aventurar pelo universo do audiovisual universitário sendo fundamental para a elaboração dos seus TCCs, caso a opção seja um produto. Dessa forma, visualiza-se que os discentes têm contato com a produção audiovisual, no mínimo, durante três semestres. $O$ que demonstra uma versatilidade e as possibilidades de se relacionar com o documento audiovisual.

\footnotetext{
${ }^{1} \mathrm{O}$ discente pode optar por realizar alguns dos laboratórios disponíveis na matriz curricular do curso de Jornalismo como, por exemplo, o Laboratório de Impresso, Fotojornalismo, Telejornalismo, Jornalismo Digital ou Assessoria de Imprensa.
} 


\section{CULTURA DO ARQUIVAMENTO AUDIOVISUAL}

No decorrer do desenvolvimento da pesquisa sobre o documento audiovisual e o processo de arquivamento, com foco em ambientes digitais - objeto de estudo da dissertação do Mestrado em Biblioteconomia -, surgiram alguns questionamentos sobre uma cultura do arquivamento nas Instituições Federais de Ensino Superior (IFES), especificamente, no âmbito audiovisual. Essa cultura existe? Ela está ou foi implantada? Como ela ocorre? São questões que possibilitam a reflexão sobre a importância e a necessidade do vislumbrar a cultura do arquivamento audiovisual, visando ao armazenamento, à disseminação e à recuperação da informação.

Partindo desses questionamentos, que não se encerram aqui e têm a missão de provocar outras pesquisas e pesquisadores sobre o processo de arquivamento audiovisual, faz-se preciso entender o que é cultura, principalmente, porque, de acordo com Canedo $(2009$, p. 1), está não "[...] é uma tarefa simples. A cultura evoca interesses multidisciplinares, sendo estudada em áreas como sociologia, antropologia, história, comunicação, administração, economia, entre outras. Em cada uma dessas áreas, é trabalhada a partir de distintos enfoques e usos." Ou seja, visualiza-se o conceito de cultura a partir de um caráter transversal, que dialoga com os diferentes campos e áreas do conhecimento. Assim, é mais propício usar o termo culturas para abarcar a pluralidade e diversidade da sua utilização. Como explica Williams (2007), a palavra cultura tem sua raiz semântica em colore, originando o termo em latim cultura, cujo significado está relacionado a habitar, cultivar, proteger e honrar.

Ao voltar os olhos para o passado, identifica-se o uso do termo cultura, até o século XVI, com o objetivo de "[...] se referir a uma ação e a processos, no sentido de ter cuidado com algo." (CANEDO, 2007, p. 2). E, nos séculos XVIII e XIX, como um período em que o uso da palavra é consolidado no meio artístico-cultural, surgindo daí expressões como "cultura das artes", "cultura das letras" e "cultura das ciências" (CUCHE, 2002; WILLIAMS, 2007). Assim, tais autores explicitam que o termo era utilizado, em conjunto com um complemento, para expressar o assunto que estava sendo cultivado - do mesmo modo em que está sendo proposta a "cultura do arquivamento audiovisual".

Com isso, Canedo (2007) destaca três compreensões de cultura:

- conceito mais alargado onde todos os indivíduos são produtores de cultura, que nada mais é do que o conjunto de significados e valores dos grupos humanos;

- atividades artísticas e intelectuais com foco na produção, na distribuição e no consumo de bens e serviços que conformam o sistema da indústria cultural; e

- instrumento para o desenvolvimento político e social, onde o campo da cultura se confunde com o campo social.

A partir dessas três dimensões, entende-se que, para a finalidade dessa pesquisa, o conceito de cultura se configura como uma atividade intelectual desenvolvida em instituições de todos os tipos, em que a finalidade está em estabelecer uma rotina para a produção, a distribuição e o consumo de serviços, bens e produtos de cunho social.

Partindo dessa ideia de cultivo e do uso de um complemento é que se propõe esta pesquisa sobre a "cultura do arquivamento audiovisual", visto que não é uma cultura que esteja presente nas IES federais, especificamente nas situadas na região Nordeste, que têm como foco os cursos de Jornalismo dessas instituições. Mas, o que seria essa cultura do arquivamento audiovisual? Na cultura do arquivamento, encontram-se bases para a proposta da construção que 
vai além do hábito de armazenar e arquivar os documentos audiovisuais. Trata-se de desenvolver os ideais de acesso, uso, disseminação e recuperação da informação. É o estabelecimento de diretrizes e de um modelo de organização que tem como finalidade a preservação de documentos audiovisuais, a partir de uma série de atividades práticas que até já podem ser vistas nos ambientes de informação, mas que não possui uma prática constante ou um fluxo de funcionamento mais ativo.

Assim, a concepção de cultura do arquivamento audiovisual perpassa o desenvolvimento de uma rotina de armazenamento da produção audiovisual, neste caso aplicado às IFES, tendo como foco a salvaguarda para que exista o acesso, a disseminação, a recuperação e o uso da informação audiovisual. É mais do que um hábito de realizar o arquivamento dessas produções; é dar visibilidade para esse tipo de documento e criar um sistema próprio de memória, principalmente, com as produções que são desenvolvidas ao longo dos cursos de graduação, como pode ser visualizado nos cursos de Jornalismo e, mais especificamente, nas disciplinas de Telejornalismo, que abarcam uma grande quantidade de produtos audiovisuais.

Existe uma necessidade de tornar tal procedimento sólido e presente nesses ambientes informacionais, que, via de regra, não possui um profissional especializado como o bibliotecário. Com isso, a formação de uma cultura do arquivamento audiovisual e a construção de uma memória social com bases nesses documentos audiovisuais permitem o fortalecimento dos cursos de Jornalismo, da sua produção, da própria IES e, também, a quebra de fronteiras da universidade, podendo se relacionar com a comunidade, em geral, e com universidades, cursos e pesquisadores interessados na área de audiovisual. Dessa forma, ampliam-se as pesquisas na área da Biblioteconomia e Ciência da Informação sobre o documento audiovisual bem como oferece um protagonismo na contemporaneidade.

Dialogando com a revolução tecnológica e com os ambientes digitais de informação, a cultura do arquivamento audiovisual e os processos já citados podem ser amplificados a partir da digitalização dos documentos. Exposta a discussão, compreende-se que a cultura do arquivamento audiovisual necessita existir nos espaços informacionais como nas IFES, dialogando com as etapas de armazenamento on-line, controle informacional, disponibilização de um resumo em conjunto com o produto audiovisual, atualização contínua conforme o fluxo de informação e disseminação, através de divulgação nos veículos institucionais, criando, em última análise, um sistema de memória audiovisual.

\section{METODOLOGIA}

A metodologia no contexto da presente pesquisa parte de uma abordagem quantiqualitativa, visto que esse tipo de abordagem possibilita compreender a realidade multifacetada (MINAYO; SANCHES, 1993) em torno do arquivamento dos documentos audiovisuais - o documentário e a grande reportagem - como o corpus da pesquisa, uma vez que se configura a partir da objetividade e subjetividade da pesquisa. Esse modelo de abordagem proporciona elementos para compreender as condições do homem, pois "a qualidade está sempre ligada a qualidade." (GRAMSCl, 1995, p. 51).

A pesquisa também se configura como exploratória, identificando a realidade do objeto de estudo dentro do espaço acadêmico. Além disso, essa exploração permite destacar as principais dificuldades em relação ao arquivamento e à disponibilização dos documentários no ambiente on-line. O recorte de coleta dos TCC audiovisuais está situado entre os períodos letivos de 2013.2 e 2019.1, que compreendem o período em que a primeira turma do curso inicia a suas apresentações do TCC até a turma mais recente que já realizou o depósito dos trabalhos. 
Em relação a coleta de dados, ela foi realizada tanto na biblioteca como na coordenação do curso de Jornalismo, buscando identificar quantos TCCs tinham sido apresentados e constavam nesses ambientes. Já em um segundo momento, buscou-se mapear os ambientes de armazenamento on-line da universidade e o do curso de Jornalismo.

Como salientado acim, a coleta de dados foi realizada na biblioteca e na coordenação do curso de Jornalismo. A opção por realizar a coleta nos dois ambientes perpassou, em um primeiro momento, a dificuldade de acesso aos documentários em ambos os lugares. Na biblioteca, o produto em si, armazenado em um DVD, não está disponível para empréstimo ou consulta, visto que apenas os relatórios estão catalogados, mas não indexados. Assim, se o usuário fizer uma busca no sistema on-line, não será possível encontrar e/ou recuperar. Já na coordenação do curso, as cópias de alguns produtos jornalísticos audiovisuais estão disponíveis. Porém, não são todos os documentos que são encontrados, organizados ou sistematizados. Para finalidades da pesquisa, o pesquisador precisou realizar a catalogação dos TCCs - incluindo as outras modalidades - possibilitando a continuação da pesquisa.

\section{ANÁLISE E DISCUSSÃO DOS RESULTADOS}

Com a coleta de dados foram identificados 22 TCCs produtos jornalísticos audiovisuais, dos quais 17 são documentários e cinco grandes reportagens. Esses documentos estão presentes desde o ano de 2013 até o primeiro semestre de 2019, conforme o Quadro 1.

Quadro 1 - Documentos audiovisuais do Curso de Jornalismo (2013.2-2019.1)

\begin{tabular}{|c|c|c|}
\hline Ano & Documentário $f(x)$ & Grande reportagem $f(x)$ \\
\hline 2013 & 2 & 1 \\
\hline 2014 & 1 & 1 \\
\hline 2015 & 1 & 0 \\
\hline 2016 & 2 & 1 \\
\hline 2017 & 5 & 2 \\
\hline 2018 & 4 & 0 \\
\hline 2019 & 2 & 5 \\
\hline Total & 17 & 0 \\
\hline
\end{tabular}

Fonte: dados da pesquisa (2020).

No gráfico 1, é possível visualizar de forma mais clara o crescimento da produção audiovisual jornalística universitária da UFCA, dentro do período de análise recortado. A escolha em produzir um documentário se apresenta com a principal escolha pelos graduandos, no contexto do produto jornalístico audiovisual.

Tanto no Quadro 1 quanto no Gráfico 1, é possível identificar que os anos de 2017 e 2018 foram mais significativos na produção de TCCs documentários, em comparação com os anteriores. Já os anos de 2013, 2016 e 2019 contam com a mesma quantidade de documentários. Porém, é importante destacar que a coleta em relação ao ano de 2019 refere-se apenas ao 
primeiro semestre (2019.1) o que pode implicar em uma contagem maior quando verificados os dados do semestre 2019.2, que ainda não está disponível.

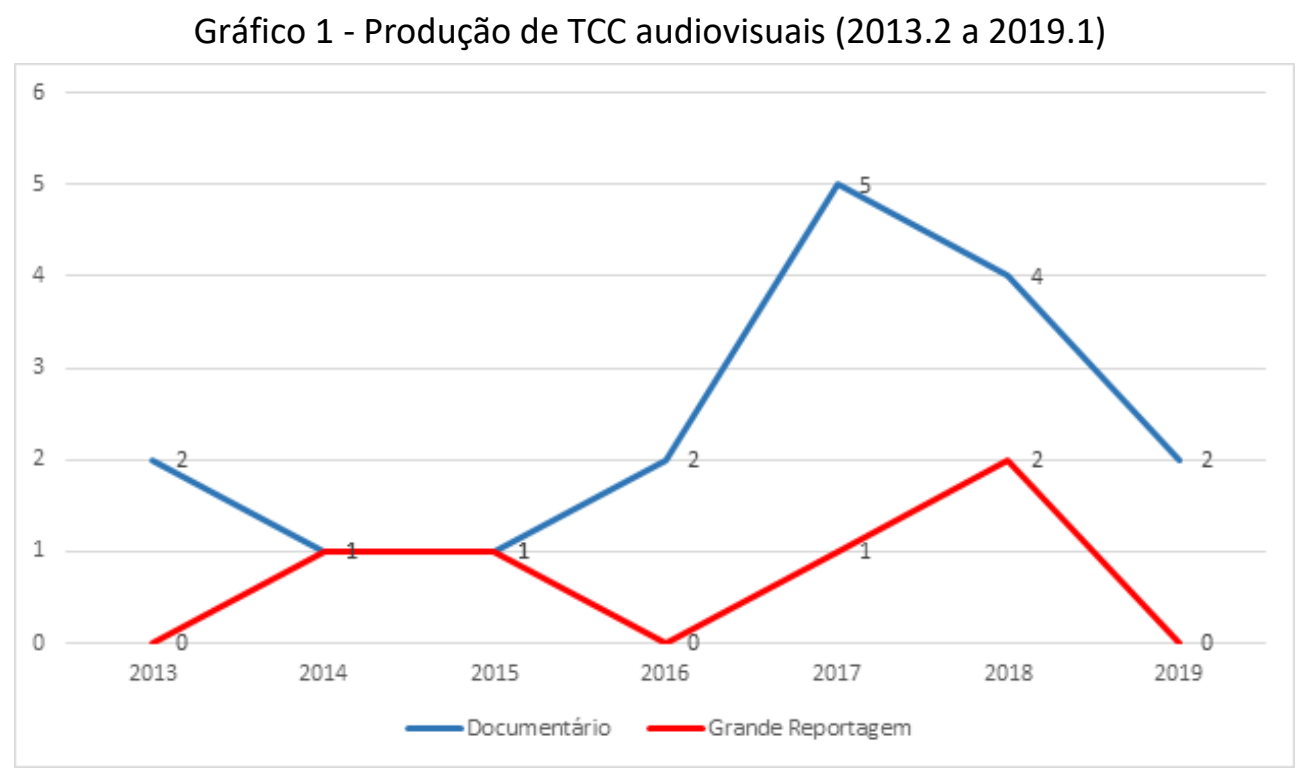

Fonte: dados da pesquisa (2020).

A quantidade de grandes reportagens em comparação com o documentário é visivelmente menor, porém, no ano de 2018 , observa-se um aumento de $100 \%$ em relação aos anos anteriores (2014, 2015 e 2017), que também tiveram em sua contagem a produção de um TCC em formato de grande reportagem.

Percebe-se o crescimento desse tipo de TCC no curso de Jornalismo, principalmente, nos anos de 2017 e 2018 em comparação com os anos anteriores. Os discentes estão voltando a sua atenção, na produção do TCC, para os produtos audiovisuais jornalísticos como uma das opções de produto jornalístico, além das monografias, que continuam sendo o modelo de TCC mais produzido.

Esse aumento na elaboração dos TCC audiovisuais enfatiza a necessidade de refletir a prática do arquivamento desses documentos, seja na versão física ou digital, tanto para o acesso e o uso quando para a sua preservação e recuperação. Porém, o que se observa é justamente a falta do arquivamento desses produtos audiovisuais de forma prática e regular.

Dessa forma, se há um crescimento na produção, pode-se inferir que exista o interesse em poder assistir ao que já foi produzido pelos discentes das turmas anteriores para observar a forma como foram feitos, as temáticas tratadas, o recorte de imagem, o enquadramento, e a estética, entre outros aspectos técnicos de produção, edição do documentário, etc. Porém, esse processo de visualização não pode ser feito já que a disponibilização não ocorre. Assim, essas memórias audiovisuais produzidas pelos discentes caem no esquecimento.

Acerca dos ambientes digitais de informação da instituição foi possível identificar alguns prováveis lugares de armazenamento: o site da própria instituição ${ }^{2}$ em que se encontra as informações do curso, o site do curso de Jornalismo ${ }^{3}$, o site da disciplina de telejornalismo ${ }^{4}$, o Sistema de Bibliotecas da UFCA ${ }^{5}$ e as redes sociais digitais como o Facebook ${ }^{6}$ e o YouTube Y $^{7}$.

\footnotetext{
${ }^{2}$ https://www.ufca.edu.br/.

${ }^{3}$ http://jornalismo.ufca.edu.br/.

${ }^{4}$ http://telejornalismo.ufca.edu.br/.

${ }^{5}$ https://catalogo.ufca.edu.br/biblioteca/index.php.
} 
É interessante observar que esses lugares para armazenamento e disponibilização no ambiente on-line não estão sendo utilizados para tal finalidade. O site do curso de Jornalismo, por exemplo, até possui uma aba para a biblioteca on-line, na qual é visualizado um espaço para a inserção dos TCC produtos audiovisuais, conforme a Figura 1. Porém, não possui nenhum registro de uso e, muito menos, de inserção desses documentos na plataforma.

Figura 1 - Biblioteca on-line do site do curso de Jornalismo

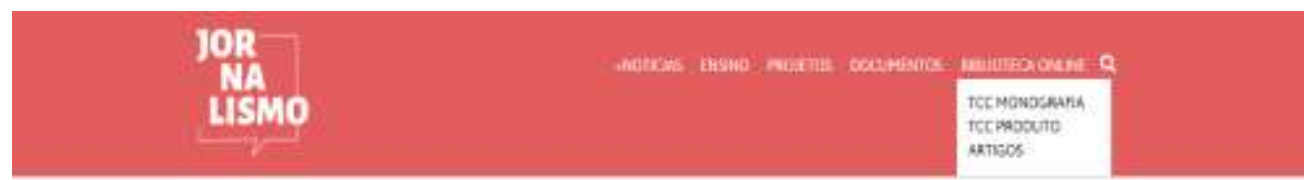

Fonte: UFCA (2019a).
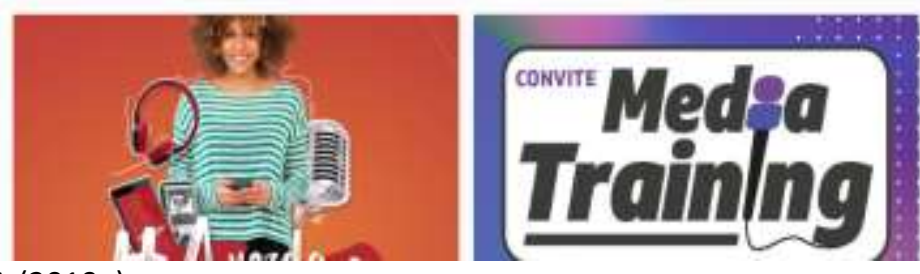

Já na fanpage no Facebook do Telejornalismo UFCA, as postagens dos vídeos encontram-se desatualizadas, observando, na Figura 2, que última postagem ocorreu no ano de 2017. Demonstrando que a concentração dos produtos audiovisuais arquivos estão no site da disciplina de Telejornalismo e no canal do YouTube.

Figura 2 - Fanpage do Telejornalismo UFCA no Facebook

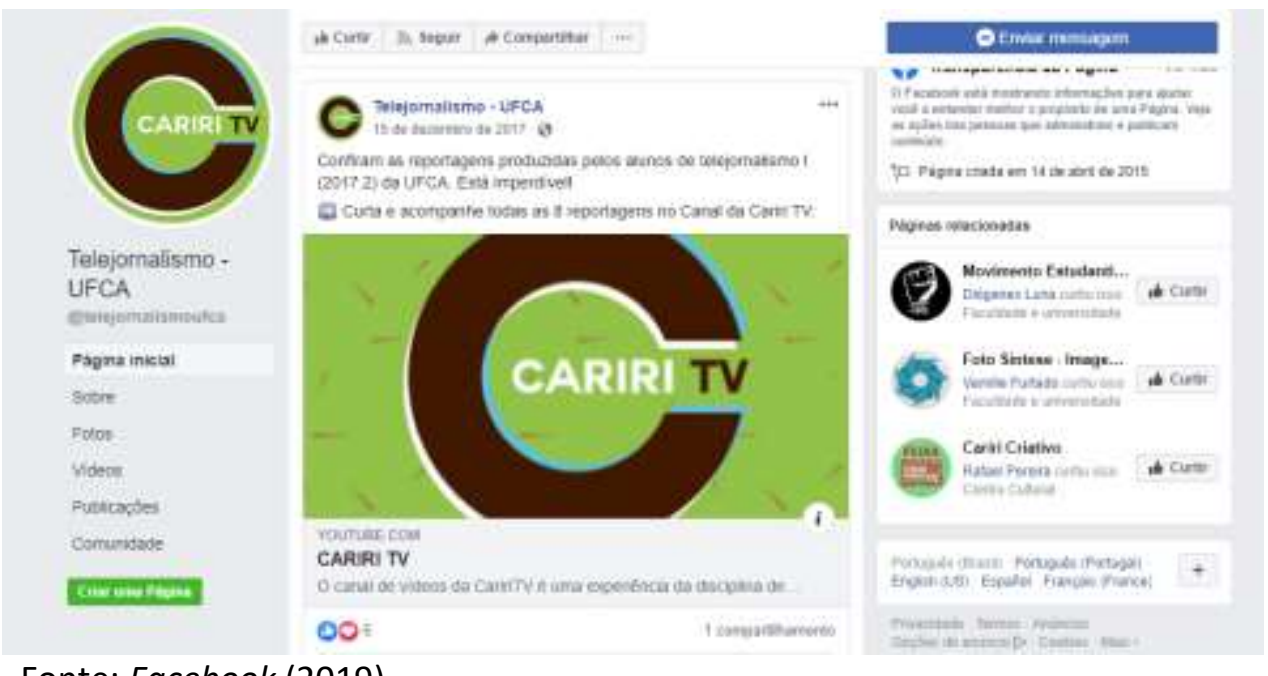

Fonte: Facebook (2019).

No site da disciplina de telejornalismo, é possível encontrar trabalhos acadêmicos inseridos na plataforma digital, tais como telejornais, programas de entrevista, debates, reportagens e documentários. Esses documentos audiovisuais estão dispostos no site na aba "produções", no item "vídeos", como se observa na Figura 3.

\footnotetext{
${ }^{6}$ https://www.facebook.com/telejornalismoufca/.

${ }^{7}$ https://www.youtube.com/user/TVComunicacaoCariri
} 
Figura 3 - Espaço para o armazenamento das produções da disciplina de telejornalismo on-line

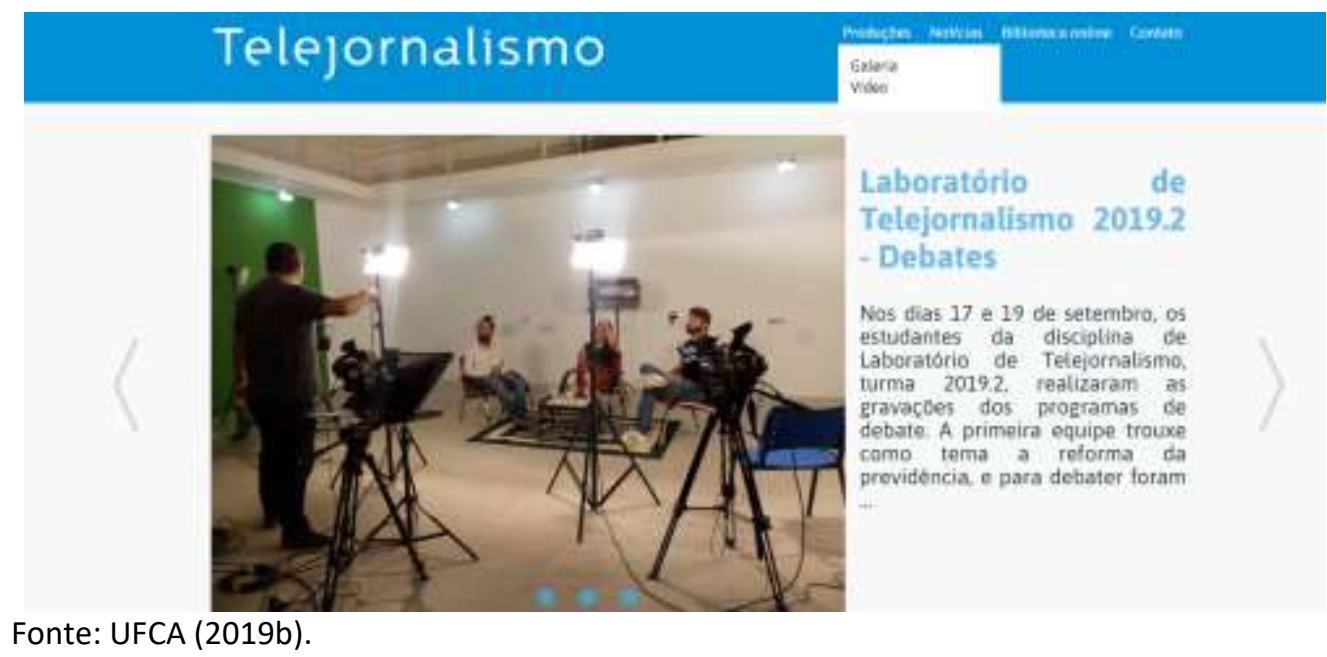

Nessas subdivisões do site, o usuário pode acessar diversas produções realizadas pelos estudantes de turmas diferentes. Nela também estão inseridas todas as produções do curso que estão disponíveis no canal do YouTube desde 2012, que antecedem a criação do site no ano de 2015, conforme Figura 4.

Assim, na aba vídeo, o usuário pode encontrar diversas produções de diferentes turmas e formatos de conteúdo audiovisual diferentes. Mas, ao procurar pelos TCC documentários, os mesmos não estão nessa plataforma on-line.

Figura 4 - Produtos audiovisuais do canal no YouTube inseridos no site de telejornalismo

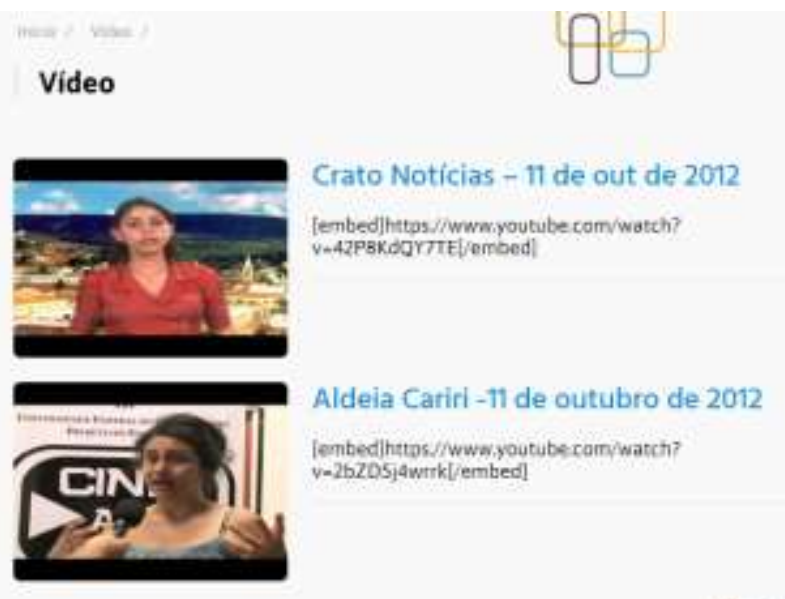

Fonte: UFCA (2019b).

A prática de arquivamento da disciplina no site foi iniciada em 2015, ano de criação deste. Mas o canal do YouTube já existia e as demais produções audiovisuais já eram nele armazenadas. O canal denominado Cariri TV foi criado em 10 de outubro de $2012^{8}$. A primeira produção arquivada data de 11 de outubro de 2012, o programa Aldeia Cariri (Figura 5), produzida pela primeira turma de jornalismo, quando a universidade ainda era a Universidade Federal do Ceará, Campus Cariri (UFC/Cariri).

\footnotetext{
${ }^{8}$ Informação disponibilizada no canal do YouTube: https://www.youtube.com/user/TVComunicacaoCariri/about.
} 
Figura 5 - Primeiro documento audiovisual arquivado no YouTube

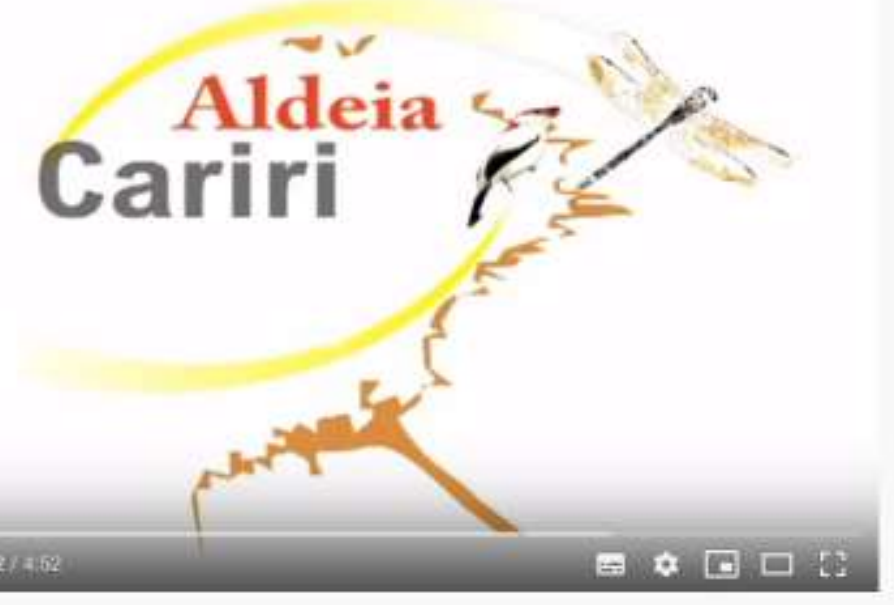

Aldeia Carii

212 visualizaçũes -11 de out, de 2012

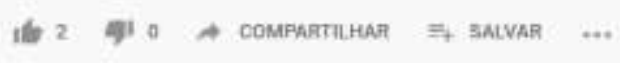

Fonte: UFC (2012).

Torna-se fundamental identificar como esses lugares para o armazenamento e o acesso ao conteúdo audiovisual possibilitam o intercâmbio acadêmico, a partir da integração e interação entre as turmas e os usuários internos e externos à instituição. Além disso, cria-se um sistema de memória audiovisual que possibilita a realização de pesquisas e a construção da paisagem audiovisual midiática universitária. O que faz falta são as produções dos TCC audiovisuais, por possuírem um peso maior, considerando que o discente já passou por todas as disciplinas e poderá apresentar um trabalho final mais elaborado e com um grau de reflexão mais profundo, em comparação com os produtos audiovisuais desenvolvidos nas disciplinas de telejornalismo, ao longo da graduação.

Em relação ao uso e acesso, sobretudo, no ambiente digital de comunicação, percebe-se que é um canal que vem adquirindo cada vez mais espaço na vida cotidiana das pessoas. Os ambientes digitais bem como os dispositivos de acesso estão em sintonia, tornando a experiência da usabilidade mais instantânea, imediata e móvel. Além disso, quebra as barreiras de tempo e espaço, ainda estabelecidas, no acesso físico, a esse tipo de material audiovisual, por exemplo.

Neste sentido, entende-se que a prática do arquivamento existe de forma unilateral em relação aos arquivos audiovisuais jornalísticos universitários, restringindo-se somente aos arquivos feitos durante as disciplinas de telejornalismo ao longo da graduação, uma vez que os TCC documentários audiovisuais não foram identificados para acesso e uso em nenhuma das plataformas digitais ou mesmo na biblioteca, onde deveria constar para esse tipo de serviço.

\section{CONSIDERAÇÕES PARCIAIS}

Diante da realidade exposta sobre o arquivamento do documento audiovisual do curso de Jornalismo da UFCA, identificou-se que os TCC produtos audiovisuais (documentários e grandes reportagens) não estão armazenados propiciando o acesso ao usuário e que a prática do arquivamento também não é uma realidade na instituição. Percebe-se que os produtos elaborados nas disciplinas de Telejornalismo estão sendo arquivados tanto no site da disciplina quanto no canal do YouTube, mas em relação aos TCC produtos audiovisuais o mesmo feito não 
ocorre, especialmente, em ambientes digitais de informação. Assim, tanto a biblioteca como a coordenação do curso de Jornalismo não demonstram uma preocupação com a disseminação desses documentos audiovisuais nos ambientes físicos e/ou digitais.

É preciso considerar que a demanda de trabalho desses lugares informacionais é grande. Porém, é importante observar que, há seis anos (2013-2019), desde os primeiros TCC produtos audiovisuais elaborados, estes não são catalogados e indexados. Assim, o ambiente universitário, visto como espaço para a reflexão, inovação e desenvolvimento de novas práticas, entra em conflito com a falta da disponibilização desses produtos audiovisuais e de uma cultura do arquivamento audiovisual. Eles são produtos que resguardam e revelam a memória da sociedade, do curso e da produção discente jornalística que permanecem guardados em uma sala, sem uma finalidade que demonstre utilidade pública.

Desse modo, as práticas, que já vem acontecendo com os produtos frutos das disciplinas de Telejornalismo, servem como exemplos para que até a própria disciplina venha a disponibilizar esses produtos. $E$, também, o site do próprio curso já que possui um espaço destinado para essa finalidade. Mas, como identificado, o que falta é de fato a cultura do arquivamento. Um processo que extrapola as fronteiras do simples arquivar, mas que visa ao compartilhamento, à guarda e à memória dos estudantes, da região e das melhorias que tanto o curso quanto a instituição estão acompanhando com o passar do tempo.

Uma proposta que poderia ser viabilizada condiz com a parceria entre o curso de Jornalismo e o curso de Biblioteconomia. Um bolsista ou uma capacitação técnica para a catalogação e indexação dos documentos audiovisuais dos TCC dos discentes pode ser visualizado como uma possibilidade prática e viável.

Neste sentido, a partir da presente pesquisa tem-se uma visão do curso de Jornalismo da UFC. Mas essa mesma realidade se apresenta em outras IFES e em outros cursos de Jornalismo? Esse processo de arquivamento do documento audiovisual se apresenta em outras instituições como lugares de memória? Existe uma cultura de arquivamento dessas produções? São questões que merecem ser colocadas em jogo para uma discussão mais aprofundada sobre o arquivamento e sobre o aprendizado para além do ato de produção documentária.

\section{REFERÊNCIAS}

BELLOTTO, H. L. Arquivos permanentes: tratamento documental. São Paulo: T. A. Queiroz Editor, 1991.

BUARQUE, M. D. Estratégias de preservação de longo prazo em acervos sonoros e audiovisuais. In: ENCONTRO NACIONAL DE HISTÓRIA ORAL, 9., 2008, São Leopoldo, RS. Anais [...] Rio de Janeiro: Associação Brasileira de História Oral; São Leopoldo, RS: UNISINOS, 2008. 9f. Disponível em: http://cpdoc.fgv.br/producao intelectual/arq/1718.pdf. Acesso em: 19 ago. 2019.

BUCKLAND, M. K. What is a "document"? Journal of the American Society for Information Science, Medford, v. 48, n. 9, p. 804-809, set. 1997. Disponível em: https://monoskop.org/images/4/4e/Buckland Michael K 1997 What is a Document.pdf. Acesso em: 19 ago. 2019.

CAJAZEIRA, P. E.; SOUZA, J. J. G. Acervo audiovisual e virtualização: as potencialidades da tecnologia digital para a preservação da memória. Rizoma, Santa Cruz do Sul, v. 7, n. 1, p. 122-135, junho, 2019. Disponível em: 
https://online.unisc.br/seer/index.php/rizoma/article/view/12823/8278. Acesso em: 19 ago. 2019.

CANEDO, D. "Cultura é o quê?" - Reflexões sobre o conceito de cultura e a atuação dos poderes públicos. In: ENCONTRO DE ESTUDOS MULTIDISCIPLINARES EM CULTURA, 5., 2009, Salvador. Anais [...] Salvador: UFBA, 2009, p. 1-14.

CUCHE, D. O Conceito de Cultura nas Ciências Sociais. Tradução de Viviane Ribeiro. 2 ed. Bauru: EDUSC, 2002.

EDMONDSON, R. Uma filosofia dos arquivos audiovisuais. Paris: UNESCO, 1998.

FACEBOOK. Telejornalismo - UFCA, 2019. Disponível em:

https://www.facebook.com/telejornalismoufca/. Acesso em: 20 jan. 2020.

GONZÁLEZ-GARCÍA, P. Los documentos en nuevos soportes. Boletim do arquivo, São Paulo, v. 1, n. 1, p. 19-37, dez. 1992.

GRAMSCI, A. Concepção dialética da história. Rio de Janeiro: Civilização Brasileira, 1995.

LE COADIC, Y. F. A ciência da informação. Tradução de Maria Yêda F. S. de Filgueiras Gomes. Brasília: Briquet de Lemos, 1996.

MINAYO, M. C. S; SANCHES, O. Quantitativo-qualitativo: oposição ou complementaridade? Cadernos de Saúde Pública, Rio de Janeiro, v. 9, n. 3, p. 239-262, jul./set. 1993. Disponível em: https://www.scielo.br/pdf/csp/v9n3/02.pdf. Acesso em: 28 jul. 2019.

PEARCE-MOSES, R. A glossary of Archival and Records terminology. Chicago: The Society of American Archivists, 2005. Disponível em: http://files.archivists.org/pubs/free/SAA-Glossary2005.pdf. Acesso em: 5 ago. 2019.

SANTOS, F. E. P. et al. Documento e informação audiovisual: bases conceituais numa perspectiva neodocumentalista. Em Questão, Porto Alegre, v. 24, n. 2, p. 235-259, maio/ago. 2018. Disponível em: https://seer.ufrgs.br/EmQuestao/article/view/76085/47504. Acesso em: 28 jul. 2019.

SOUZA, J. J. G.; CAJAZEIRA, P. E. Mas, afinal o que é uma websérie digital? In: CONGRESSO BRASILEIRO DE CIÊNCIAS DA COMUNICAÇÃO, 38., 2015, Rio de Janeiro. Anais [...] Rio de Janeiro: Intercom, 2015. p. 1-15. Disponível em:

http://portalintercom.org.br/anais/nacional2015/resumos/R10-1215-1.pdf. Acesso em: 5 ago.2019.

UNIVERSIDADE FEDERAL DO CARIRI (UFCA). Biblioteca on-line. Jornalismo, Juazeiro do Norte, 2019a. Disponível em: http://jornalismo.ufca.edu.br/category/tcc produto/. Acesso em: 10 jan. 2020. 
UNIVERSIDADE FEDERAL DO CARIRI (UFCA). Projeto Pedagógico do Curso de Jornalismo. Juazeiro do Norte: UFCA. 2016. Disponível em: https://documentos.ufca.edu.br/wp-folder/wpcontent/uploads/2019/08/JornalismoUFCA-Projeto-Pol\%C3\%ADtico-Pedag\%C3\%B3gico2016.pdf. Acesso em: 6 dez. 2019.

UNIVERSIDADE FEDERAL DO CARIRI (UFCA). Telejornalismo. Galeria vídeos. Jornalismo, Juazeiro do Norte, 2019b. Disponível em: http://telejornalismo.ufca.edu.br/category/producoes/. Acesso em: 10 jan. 2019.

UNIVERSIDADE FEDERAL DO CEARÁ (UFC). Aldeia cariri. YouTube, 2012. Disponível em: https://www.youtube.com/user/TVComunicacaoCariri/. Acesso em: 10 jan. 2019.

VIEIRA, T. O. Os documentos audiovisuais, iconográficos e sonoros: uma análise dos atores e suas produções acadêmicas. In: BLANCO, P. S.; SIQUEIRA, M. N.; VIEIRA, T. O. (Orgs.). Ampliando a discussão em torno de documentos audiovisuais, iconográficos, sonoros e musicais. Salvador: EDUFBA, 2016. p. 47-72. Disponível em:

https://repositorio.ufba.br/ri/bitstream/ri/20828/3/Ampliando-a-Discussao RI.pdf. Acesso em: 5 ago. 2019.

WILLIAMS, R. Palavras-chave: um vocabulário de cultura e sociedade. Tradução de Sandra Guardini Vasconcelos. São Paulo: Boitempo, 2007. 